\title{
Knowledge, moral claims and the exercise of power in global health
}

\author{
Jeremy Shiffman*
}

\section{Abstract}

A number of individuals and organizations have considerable influence over the selection of global health priorities and strategies. For some that influence derives from control over financial resources. For others it comes from expertise and claims to moral authority - what can be termed, respectively, epistemic and normative power. In contrast to financial power, we commonly take for granted that epistemic and normative forms of power are legitimate. I argue that we should not; rather we should investigate the origins of these forms of power, and consider under what circumstances they are justly derived.

Keywords: Epistemic Power, Global Health, Politics of Health

Copyright: @ 2014 by Kerman University of Medical Sciences

Citation: Shiffman J. Knowledge, moral claims and the exercise of power in global health. Int J Health Policy Manag 2014; 3: 297-299. doi: 10.15171/ijhpm.2014.120
Article History:

Received: 15 October 2014 Accepted: 7 November 2014 ePublished: 8 November 2014

\author{
${ }^{*}$ Correspondence to: \\ Jeremy Shiffman \\ Email: jshiffma@american.edu
}

$\mathrm{P}$ ower is exercised everywhere in global health although its presence may be more apparent in some instances than others. We commonly recognize an attempt to exert it when a pharmaceutical company insists it will invest in a country only if the government alters patent protection laws, when the World Bank demands as a loan condition that a borrowing government undertakes major health sector reforms, and when a bilateral donor allocates health aid according to its geopolitical interests rather than humanitarian need. By contrast, we may not recognize its exertion-or not call it such-when a Lancet special issue promotes a particular strategy to address malnutrition, when the Institute for Health Metrics and Evaluation (IHME) disseminates a new version of its Global Burden of Disease (GBD) study, or when North American AIDS activists press to ensure inclusion of universal access to anti-retroviral drugs in global development goals. Yet if we understand power to be the production of effects that shape the capacity of others to determine their own circumstances or fates, as political scientists have argued (1), then all these instances count as attempts to exert power.

We traditionally understand power in compulsory terms, as the direct control of one actor over another. The classic definition is by Robert Dahl (2): "A has power over B to the extent that he can get $B$ to do something that $B$ would not otherwise do". The pharmaceutical company example above is an instance. But there are several other forms. Among others is structural power $(1,3)$ : how we define ourselves in relationship to one another, in ways that enhance the capacities of some and limit those of others. A stark historical example is master and slave. Also, there is productive power (1): how we create meaning, particularly through the use of categories that lead us to think about the world in some ways but not others.

In global health we see structural power at work in the existence of a cadre of individuals-medical professionals, development economists, advocacy experts and others- who offer advice to governments of low-income countries presumed to be in need of their input. And we see productive power at work as they create concepts for thinking about health priority-setting, such as burden of disease, treatment cost-effectiveness and the right to receive care.

In seeking to exert power, actors may claim expertise concerning the biomedical causes of a condition, its prevalence, broader determinants of health, appropriate policy responses, or interventions needed to address or avert illness. Examples include officials and researchers in universities and international organizations such as the World Health Organization (WHO) and World Bank. Actors may also claim insight concerning ethical principles we ought to follow as we make decisions about improving population health-for instance human rights lawyers, and activists promoting sexual and reproductive health or population stabilization. Each of these two kinds of assertions-epistemic and normative-invoke both structural and productive power: an implicit or explicit declaration about 1) the status of the claimant vis-à-vis those whose behavior he or she intends to shape, and 2) the validity of the categories he or she uses to express the needed changes.

In contrast to power that comes from control over financial resources, we commonly take these forms of power to be legitimate, by virtue of their grounding in knowledge or humanitarian motives. I argue that we should not do so, but rather inquire into the sources of such power, and consider the circumstances under which its exertion is justifiable.

There are several reasons to raise such questions. First, these forms of power are widespread, yet little analyzed or understood. Why do some individuals become recognized as global health experts? Why are some organizations (for instance Doctors without Borders) afforded legitimacy while others are frequently attacked (for instance the World Bank)? Do these differences arise simply as a result of the behavior of the actors, or are they due to more complex social processes? 
Second, the exertion of these powers raises normative questions surrounding legitimacy and accountability. On what basis does one acquire a right to exert such power? Is it sufficient to show that one is motivated by a humanitarian impulse and/or has made a positive difference, or must we consider additional criteria surrounding fair process and deliberation? (4). And how should we hold those who exert power accountable? Third, far from being in opposition, improving health requires exerting epistemic and normative power, particularly to expand service access and to alter social structures that lead to illness and death. Many in the global AIDS movement operate from just such a premise.

Three examples-concerning leadership in the health metrics field, the emergence of the Lancet as a global health actor, and the formation of the post-2015 health development goalshelp to illustrate why investigating epistemic and normative power may be useful:

1. There is now significant contestation concerning leadership in the health metrics field. Much is due to the emergence of the IHME, a University of Washingtonbased, Gates Foundation-supported non-governmental organization, formed in 2007. Its signature products are GBD studies, which the Institute states aim to provide impartial information on health loss due to variety of conditions (5). The formation of the IHME represented a challenge to the WHO, among other organizations, which had traditionally served as a global leader in the production of health metrics (6). Several major disagreements have emerged between the two, including heated conflicts over global malaria estimates (7). While there is no obvious reason to question the Institute's commitment to the conduct of impartial science, IHME and its GBD studies have been criticized on a number of grounds, several of which form the backdrop for conflict with the WHO over leadership $(6,8-10)$. These include providing insufficient information about data sources, excluding important disease sub-categories, devaluing the lives of people living with disabilities, undertaking inadequate external consultation, and acting as a competitor rather than a collaborator in the health metrics field. These critiques, and contestation with the WHO, suggest that the exercise of epistemic power is a central issue in a seemingly impartial, neutral undertaking: the production of data concerning disease burden.

2. Over the past two decades a medical journal-the Lancet-has emerged as one of the most powerful actors in global health. One of the world's most highly cited publications, the Lancet's heavy involvement in global health emerged in the late 1990s, when it initiated a special series on global health. To date the journal has published more than 100 such series (http://www. thelancet.com/global-health-series), several backed by donors. Most recently, the Lancet has organized a number of commissions intended to spur action on global health issues, including the health implications of climate change and health investment. These series and commissions have influenced policy in low- and middleincome countries (11-13). By organizing these series and commissions, the Lancet has emerged as a strong voice in global health, and as a powerful convening forum for scholars and officials to express their ideas on what the world should do to advance health-one that potentially rivals traditional venues such as the World Health Assembly in its visibility and influence. That being said, unlike other publication types there are valuable checks on what appears in the journal, as articles must go through peer review, forcing authors to respond to critiques and opposing points of view. Still, the emergence of the Lancet in such roles raises some interesting questions concerning the exertion of epistemic and normative power. What are the benefits and disadvantages of a medical journal undertaking such activities in the global health field? Which issues are more likely to receive a hearing, and which may be neglected? Whose voices are privileged by this phenomenon? Whose are missed? How is the power of other global health actors enhanced or diminished, including researchers in medical and public health schools, the WHO, the World Bank, the Global Fund, and civil society movements?

3. The Millennium Development Goals (MDGs) expire in 2015. Three of the eight focus on health (goal four on child survival, five on maternal survival and six on HIV/ AIDS and other major diseases). The United Nations has convened several meetings to consider which health objectives to include in a set of post-2015 development goals. A task force report on these consultations suggests disagreement among actors concerning whether the new health goals should focus on achieving new MDGlike objectives, ensuring universal health coverage, facilitating an increase in healthy life-years, or some combination of these objectives (14). Most recently, there are proposals to include health as one of seventeen Sustainable Development Goals (SDGs), with targets that pertain to each of these three objectives. Unlike the MDGs, which were designed by a small group of officials in the UN secretariat (15), the Task Force Team carried out numerous consultations with governments and other actors (http://www.worldwewant2015.org/ health). It is unclear, however, how certain proposals got on the table and others did not (16), and by what process final decisions on priorities will be made. Like the two examples above, the formation of the post-2015 health development goals raises interesting questions about the exercise of epistemic and normative power in global health: specifically, whose voices matter most in shaping global health priorities, and how they exert influence.

In sum, although some of the actors in these three undertakings may argue otherwise, there are strong reasons to believe that more than careful, rational, pluralistic deliberation is involved in each. Each undertaking may involve the exercise of structural power by setting up particular individuals as global health experts whose advice ought to be accepted by allegedly information-deprived low-income governments. Each may be exercising productive power by shaping a global discourse surrounding particular categories to use to think about health, and why we should pursue health 
development in the first place. Specifically, the IHME may be shaping a global discourse focused on health burden rather than rights or social determinants. The Lancet may be setting itself up as an alternative forum for global health deliberation and signaling to the world which issues should be prioritized and which individuals should be listened to in order to make such a determination. And the United Nations post-2015 health development goal-setting process may be privileging some issues whose backers are particularly adept at global lobbying and advocacy, while sidelining other issues whose backers lack such access or capacity. This is not to suggest that these are all examples of illegitimate uses of power-in several respects they may be vast improvements over past prioritysetting processes and may offer voice to those who previously lacked expression. It is to suggest that these examples indicate that there is far more to global health decision-making than careful consideration of evidence, and a critical need to investigate how epistemic and normative power get exercised in the global health field.

\section{Ethical issues}

Not applicable.

Competing interests

Author declares that he has no competing interests.

Author's contribution

JS is the single author of the manuscript.

References

1. Barnett M, Duvall R. Power in International Politics. Int Organ 2005; 59: 39-75. doi: 10.1017/S0020818305050010

2. Dahl RA. Who governs? Democracy and power in an American city. New Haven, CT: Yale University Press; 1961.

3. Bourdieu P. Sociology in Question. London Oaks, CA: Sage; 1993.

4. Daniels N. Accountability for reasonableness in private and public health insurance. In: Coulter A, Ham C, editors The global challenge of health care rationing. Buckingham: Open University
Press; 2000. p. 89-106.

5. Murray CJL, Ezzati M, Flaxman AD, Lim S, Lozano R, Michaud C, et al. GBD 2010: design, definitions, and metrics. Lancet 2012; 380: 2063-6. doi: 10.1016/s0140-6736(12)61899-6

6. Cohen J. A Controversial Close-Up Of Humanity's Health. Science 2012; 338: 1414-6. doi: 10.1126/science.338.6113.1414

7. Chambers RG. UN envoy's response to estimates of global malaria mortality. Lancet 2012; 379: 707 . doi: 10.1016/s01406736(12)60280-3

8. Bickenbach JE. Disability, Justice and Health Systems Performance Assessment. In: R. Rhodes M.P. Batton, A. Silvers, editors. Medicine and Social Justice: Essays on the Distribution of Health Care. Oxford: Oxford University Press; 2002.

9. Byass P, Courten Md, Graham WJ, Laflamme L, McCaw-Binns A, Sankoh OA, et al. Reflections on the Global Burden of Disease 2010 Estimates. PLoS Med 2013; 10: 1-5. doi: 10.1371/journal. pmed.1001477

10. Watts $C$, Cairncross $S$. Should the GBD risk factor rankings be used to guide policy? Lancet 2012; 380: 2060-1. doi: 10.1016/ s0140-6736(12)62121-7

11. Lawn JE, Cousens SN, Darmstadt GL, Bhutta ZA, Martines J, Paul V, et al. 1 year after The Lancet Neonatal Survival Serieswas the call for action heard? Lancet 2006; 367: 1541-7. doi: 10.1016/s0140-6736(06)68587-5

12. Gillespie S, Haddad L, Mannar V, Menon P, Nisbett N. The politics of reducing malnutrition: building commitment and accelerating progress. Lancet 2013; 382: 552-69. doi: 10.1016/ s0140-6736(13)60842-9

13. Patel V, Garrison P, de Jesus Mari J, Minas H, Prince M, Saxena $\mathrm{S}$, et al. The Lancet's Series on Global Mental Health: 1 year on. Lancet 2008; 372: 1354-7. doi: 10.1016/s0140-6736(08)61556-1

14. World Health Organization (WHO), The United Nations Children's Fund (UNICEF), Government of Sweden, Government of Botswana. Health in the post-2015 Agenda. Report of the Global Thematic Consultation on Health. [cited October 1, 2014]. Available from: http://www.worldwewant2015.org/health

15. Fukuda-Parr S, Hulme D. International Norm Dynamics and the "End of Poverty": Understanding the Millennium Development Goals. Global Governance 2011; 17: 17-36.

16. Buse K, Hawkes S. Health post-2015: evidence and power. Lancet 2014; 383: 678-9. doi: 10.1016/s0140-6736(13)61945-5 